\title{
Avaliação externa como impulso para a melhoria das intervenções pedagógicas
}

\author{
Dulcelina Da Luz Pinheiro Frasseto* \\ Inês Odorizzi Ramos**
}

\begin{abstract}
Resumo
O presente artigo relata a pesquisa realizada em uma escola da região de Joinville, Santa Catarina, com o objetivo de identificar os possíveis fatores que influenciaram o aumento da nota na Prova Brasil, o que resultou também no aumento da média do Índice de Desenvolvimento da Educação Básica-IDEB, da referida instituição. Esse índice tem como objetivo principal avaliar os estudantes da rede pública, usando como referenciais dois indicadores calculados pelo desempenho obtidos pelos alunos na Prova Brasil e nas informações do censo escolar quanto às taxas de aprovação. Para análise neste artigo, utilizaremos apenas o quantitativo da Prova Brasil, resultado aferido aos alunos pela avaliação realizada, fazendo algumas considerações acerca do outro indicador, o de aprovação. A pesquisa configurou-se na realização e aplicação de um questionário dirigido ao corpo docente da unidade escolar, com perguntas sobre as mudanças significativas ocorridas na escola, nos anos de 2010 e 2011, períodos em que sucederam a última Prova Brasil, que os participantes acreditam ter contribuído para o aumento expressivo da média do IDEB. Constatamos também que essas mudanças trouxeram melhorias no processo de aprendizagem dos alunos inseridos nesse processo.

Palavras Chaves: Avaliação externa; Aprendizagem; Estratégias Pedagógicas.
\end{abstract}

\section{External assessment as a boost for the improvement of educational assistance}

\begin{abstract}
This article reports on research conducted in a school in the region of Joinville, Santa Catarina, with the objective of identifying the factors that influenced the increasing in the student's evaluation level in Prova Brasil test, which also resulted in the increase of the average Index for Basic Education Development-IDEB of that institution. This index aims at assessing students from Public Schools, using two indicators as benchmarks calculated by the performance obtained by the students in Prova Brasil test and information about the school census approval rates. For the analysis in this article, we use only the Prova Brasil test students' grade measured by outcome evaluation, making some considerations about the other indicator, the approval. The research rely on the creation and application of a questionnaire addressed to the faculty of the school unit, with questions about the significant changes occurring in school, in 2010 and 2011, periods that followed the last Prova Brasil test, which participants believe have contributed to the significant increase of the average IDEB, and the fact that these changes have brought improvements in the learning process of the students included in this process.

Key words: External Evaluation, Learning, Pedagogical Strategies.
\end{abstract}

\section{Introdução}

Este artigo é resultado de um estranhamento das pesquisadoras em relação à melhoria significativa das médias alcançadas pelos alunos de uma escola pública de Joinville, na avaliação da Prova Brasil no ano de 2011, sendo este um dos indicadores do Índice de Desenvolvimento da Educação Básica-IDEB. Por questões éticas e normatização de pesquisas científicas, informamos que os dados, bem como o nome da instituição pesquisada, foram autorizados para divulgação pela equipe gestora e pedagógica da escola. A assinatura do termo de livre consentimento encontra-se aos cuidados das pesquisadoras.

A referida unidade escolar, intitulada EEB

* Endereço eletrônico: dulcefrasseto@ hotmail.com

** Endereço eletrônico: ines.odorizzi@ yahoo.com.br
Senador Rodrigo Lobo, situa-se no bairro Jardim Sofia na cidade de Joinville, estado de Santa Catarina. Essa escola atende a 450 alunos da Educação Básica, nas etapas de ensino fundamental e médio.

O citado estranhamento corresponde a uma sensação de incômodo, como cita MORÃES E GUIMARÃES (2010, p.45), mas agradável incômodo - vontade de saber mais e entender tudo. Com esse objetivo, partimos para a pesquisa na tentativa de compreender quais maneiras, ou melhor dizendo, quais estratégias foram utilizadas tanto pelos sujeitos que ensinam como as utilizadas pelos sujeitos que aprendem, para desenvolver um aprendizado, demonstrado no resultado da avaliação, como mais significativo. 
Em 2009 a referida escola alcançou nota 2,0 na média do IDEB nas $8^{\circ}$ séries e 3.2 nas $4^{\mathrm{a}}$ séries, esta caracterizou a menor classificação no ranking das escolas do município de Joinville, assim como um dos mais preocupantes resultados do estado de Santa Catarina. Dois anos após esse resultado, na prova de 2011, a média alcançada foi de 5.8 nas turmas de $5^{\circ}$ anos e 6.2 nas turmas de $8^{\circ}$ séries. Essa nomenclatura refere-se ao Ensino Fundamental de oito anos; as escolas da rede estadual de Joinville ainda utilizam a matriz de oito anos nas duas séries finais do Ensino Fundamental em 2012. Esse resultado caracterizou um aumento significativo, principalmente se analisarmos somente a nota da Prova Brasil, sem levarmos em conta o índice de aprovação, outro indicador utilizado para compor a nota do IDEB.

O artigo, além da introdução e considerações finais, está organizado em três momentos: no primeiro, será feito uma análise teórica do IDEB, suas perspectivas e impacto na realidade escolar; no segundo, traremos os dados relativos à instituição pesquisada, suas características sociais, público atendido e a comunidade na qual está inserida; como terceiro enfoque, será feita a análise dos dados obtidos através do questionário utilizado na pesquisa de campo, com o intuito de identificar as possíveis mudanças ocorridas na unidade escolar que possam ser responsáveis pela elevação da média atingida na prova Brasil.

\section{Avaliação externa: Índice de Desenvolvimento da Educação Básica - IDEB}

O Brasil preconiza desde a década de 80, com a promulgação da Constituição Federal, a universalização do Ensino Fundamental, garantindo sua obrigatoriedade e a qualidade dos serviços oferecidos (BRASIL, 1988, Art 206). Para aferir a qualidade na educação, o aparato legal idealizou mecanismos de avaliação que, na década de 90, tornaram-se realidade com a promulgação da Lei 9394/96-LDB, que no seu artigo $9^{\circ}$ reafirma a necessidade de avaliações externas como pressuposto para garantir a qualidade na educação,

[...] VI - assegurar processo nacional de avaliação do rendimento escolar no ensino fundamental, médio e superior, em colaboração com os sistemas de ensino, objetivando a definição de prioridades e a melhoria da qualidade do ensino (BRASIL,
1996).

Diante da necessidade de cumprir com a referida legislação, foi lançado em 2007 o Plano de Desenvolvimento da Educação PDE, juntamente com o Decreto $\mathrm{n}^{\circ}$ 6.094, que estabelece o Plano de Metas Compromisso Todos pela Educação. O PDE, em março de 2009, abarca 41 ações; pode-se dizer que esse plano abrange quase todos os programas do Ministério da Educação. Nesse contexto, o MEC lançou o Índice de Desenvolvimento da Educação Básica-IDEB (SAVIANI, 2009, p.5). O Índice de Desenvolvimento da Educação Básica, o IDEB, foi criado em 2005, com o objetivo de avaliar a aprendizagem dos alunos de cada escola e de cada rede de ensino. O indicador é calculado com base no desempenho do estudante em avaliações do INEP Instituto de Estudos e Pesquisas Educacionais Anísio Teixeira (INEP/MEC) e em taxas de aprovação/reprovação registrado no Censo escolar. Assim, para que o IDEB de uma escola ou rede de ensino cresça, é preciso que o aluno aprenda, não repita o ano e frequente a sala de aula (MEC, 2010).

No início do programa, em 2005, o índice nacional alcançou a média de 3.8; após esse resultado, o INEP estabeleceu metas progressivas para alcançar uma melhoria, não somente do índice mas também da qualidade desta educação. Foi estipulada como meta para o ano de 2022 a média de 6.0. Esse percentual está em consonância com as metas atingidas pelos países que compõem a Organização para a Cooperação e Desenvolvimento Econômico - OCDE. A data de 2022 foi estabelecida por ser esse o ano de comemoração dos 200 anos da Independência política do Brasil (SAVIANI, 2009, p.7).

Nessa perspectiva esse índice é calculado a cada dois anos, por meio de uma avaliação - Prova Brasil - e juntamente com os dados do Censo Escolar, com relação à aprovação dos alunos. A referida prova é realizada ao final dos anos iniciais do Ensino Fundamental $-5^{\circ}$ anos e ao final do Ensino Fundamental $-9^{\circ}$ anos. A Prova Brasil segue um modelo de testes padronizados, agregando um questionário socioeconômico, com o intuito de avaliar a qualidade do ensino em todo território nacional. Os testes são aplicados em duas áreas do conhecimento, Língua Portuguesa e Matemática, medindo a leitura e o raciocínio lógico, mediante a resolução de problemas.

A busca pela qualidade na educação, tanto no Brasil quanto em qualquer outro país, não é tarefa fácil. Detectar onde estão suas falhas, em 
quais pontos deve-se atacar, tornam-se um importante passo para o enfrentamento do problema que está posto, quando nos referimos à educação que queremos ter. $\mathrm{O}$ fato de termos essa questão como meta de políticas públicas e de programas educacionais já deve ser considerado um avanço, e, mais ainda, o fato de construirmos instrumentos que possam se configurar em norteadores de intervenções é, com certeza, um passo de considerável relevância. Nesses termos, o IDEB, como instrumento de avaliação, com a proposta de melhoria da qualidade na educação, embora não nos dê garantias de obtenção de êxito, apresenta indicadores que, podemos afirmar, no âmbito das escolas acabam por gerar discussões e tomadas de decisões, no que concerne à busca de práticas pedagógicas mais eficientes e até mesmo a consciência das falhas no percurso pedagógico.

Para Saviani, o IDEB, em termos de instrumento avaliador, já avançou se comparado ao sistema anterior:

Tal índice avança em relação aos mecanismos anteriores de avaliação por não se restringir à quantidade. Ao contrário, ao trabalhar com indicadores de qualidade, O IDEB permite que as ações se voltem principalmente para as redes $e$ escolas públicas mais precárias, enfrentando, em consequência, o problema da equidade, sem o que,na perspectiva da concepção que orienta o PDE, não será resolvido o problema da qualidade na educação básica (SAVIANI, 2009, p.18).

Apesar dos avanços que traz para a avaliação da educação brasileira, somente a aplicação desse índice não significa que se possa configurar em uma melhoria da qualidade na educação básica do país. A avaliação deve ser agregada a uma proposta pedagógica que contemple uma qualidade real, aquela que vai ao encontro dos anseios da comunidade escolar, eleita por todos, pais, professores e gestores, pois o que temos proposto, medido pelos indicadores, é um ideal de qualidade definido por um modelo padrão, das escolas que apresentam um modelo a ser seguido, sem levar em conta o contexto escolar. Seria essa a educação de qualidade que queremos para nossas escolas, ou para todas as escolas independentes da comunidade na qual estão inseridas? Dentro desse modelo padrão de qualidade, estão todos os alunos incluídos, como prega nossa Constituição Federal?
(BRASIL, 1988).

Norteando-se pela perspectiva de que o IDEB possa trazer uma mudança nos fazeres pedagógicos das escolas, tendo como resultado uma melhoria nas intervenções por parte dos docentes, esta pesquisa busca identificar quais dessas intervenções trouxeram um diferencial mostrado pelos resultados da avaliação externa, pautando-se também por uma mudança significativa no interior da escola.

\section{IDEB nas escolas da rede estadual de Joinville}

O município de Joinville, localizado na região nordeste do estado de Santa Catarina, caracteriza-se como uma cidade industrial, a mais populosa e com 1130,878 $\mathrm{km}^{2}$ de área. Na organização estadual a cidade é sede da Secretaria de Desenvolvimento Regional-SDR, a qual é composta por 8 municípios, localizados no entorno. $\mathrm{Na}$ área educacional conta com o ensino público, a rede estadual e a rede municipal, bem como escolas de ensino privado, três universidades, sendo uma estadual, uma federal e outra privada, tendo ainda várias outras instituições de ensino superior. A rede estadual de ensino possui 61 escolas distribuídas em 8 municípios que compõem a regional de Joinville. Dentre essas, 10 escolas possuem somente o ensino fundamental e 4 possuem somente o ensino médio, contando também com um Centro de Educação Profissional-CEDUP, um Centro de Educação de Jovens e Adultos-CEJA e 6 escolas Indígenas.

O Índice de Desenvolvimento da Educação Básica de 2011-IDEB, foi considerado pela equipe pedagógica da Gerência de Educação de Joinville, órgão responsável pelas unidades escolares da região de Joinville Santa Catarina, como um salto de qualidade em comparação à última avaliação realizada em 2009. Das 56 escolas avaliadas nas turmas de $5^{\circ}$ anos, 19 escolas atingiram o índice acima da média da rede municipal de Joinville, 10 escolas ficaram acima da média do estado de Santa Catarina, 14 escolas ultrapassaram a média nacional e somente 7 escolas ficaram abaixo da média prevista pelo MEC para o ano de 2011 e 6 não pontuaram (INEP/IDEB 2011).

Podemos destacar também como promissores os resultados obtidos nas turmas de $8^{\mathrm{a}}$ série, sendo que 10 escolas ficaram acima da media da rede municipal de Joinville, 19 acima da média do estado de Santa Catarina, 19 escolas acima da média nacional, e 4 escolas não atingiram a media proposta pelo MEC, e 4 não pontuaram 
(INEP/IDEB 2011).

Esse resultado mostra que houve um avanço significativo na qualidade da educação da rede estadual, pois quase a totalidade das escolas não só cumpriu com as metas estabelecidas para 2011, estipulada em 4.6 para os anos iniciais e 3.9 para os anos finais do ensino fundamental, como as ultrapassou. A partir desses dados propomos um estudo de caso etnográfico, fazendo uma pesquisa de campo na Escola de Educação Básica Senador Rodrigo Lobo, instituição localizada no município de Joinville, pertencente à rede estadual de ensino. Essa unidade escolar foi a que mais se destacou no resultado do IDEB, cumprindo com as metas do MEC, proposta para 2011, tanto nos anos inicias $\left(5^{\circ}\right.$ ano) quanto nos anos finais ( $8^{\circ}$ série).

\section{Caracterização do objeto de estudo: a escola}

A instituição estadual pesquisada localiza-se no bairro Jardim Sofia, região norte do município de Joinville, com aproximadamente quatro mil habitantes, construída em 1990. Ao longo dos anos a Escola foi passando por inúmeras modificações estruturais, como o aumento do número de salas de aulas e a construção da quadra poliesportiva coberta. Tal fato, em grande parte, deveu-se à significativa expansão do número de alunos e à necessidade de abertura de novas séries. Atualmente a escola conta com 450 estudantes no período diurno e noturno, distribuídos em turmas do Ensino Fundamental e Ensino Médio. Mediante visitas feitas in loco, as pesquisadoras puderam constatar que são assegurados espaços adequados e facilitados, métodos, técnicas e recursos pedagógicos e tecnológicos para atender a todos os alunos; ela encontra-se também adequada ao atendimento aos educandos com deficiências em consonância com a legislação vigente. (Lei Complementar 170/98, Art. 64, e Resolução $112 / \mathrm{CEE} / \mathrm{SC}$ ).

Durante a pesquisa de campo foram realizadas visitas para a coleta de dados dos documentos da escola, bem como análise do Projeto Político Pedagógico-PPP. De acordo com o que está posto nos documentos, a escola conta com uma equipe pedagógica administrativa composta pelos seguintes membros: um gestor, uma assessora de direção, uma Assistente Técnica Pedagógica e uma Assistente de Educação, com um corpo docente de 23 professores contratados em caráter temporário (ACT) e 10 professores do quadro efetivo. O corpo discente da escola está matriculado e distribuído em três turnos, matutino, vespertino e noturno. Nos documentos que nortearam a pesquisa, está clara a visão de educação que perpassa as ações da escola, estabelecendo como critério que

a sociedade está em constantes transformações, portanto não se pode formar um sujeito que apenas repita o que o educador ensinou, mas propiciar o desenvolvimento de um cidadão, crítico, autônomo, responsável, autodidata, polivalente, que possa atuar numa sociedade democrática ( PPP 2012, p.12).

Para nortear os trabalhos da escola, a equipe pedagógica entende que é necessário discutir a educação fundamentando-se em vários pensadores e teóricos, pois eles se apresentam como uma maneira de transformar a sociedade e os indivíduos. Dessa forma, a instituição educacional propicia reflexões acerca da realidade em que está inserida:

realizar inicialmente um trabalho coerente e eficaz na comunidade do Jardim Sofia oferecendo reais condições de exercício da cidadania, dando conta das necessidades básicas do desenvolvimento humano, respeitando o pluralismo de concepções, possibilitando a construção de seres humanos ativos, capazes de interagir com o meio social, um ser humano fraterno, solidário que acredite na possibilidade de transformar o mundo e a sua história (PPP, 2012).

A equipe escolar possibilita momentos de participação, solidariedade, cooperação e responsabilidade entre os alunos e desses com todos os profissionais de educação. Promovem situações desafiadoras em que o aluno pode atuar, conhecer, refletir e transformar sua realidade, apropriando-se do conhecimento historicamente acumulado, ampliando seus conhecimentos e elaborando diversos outros. Ainda como referência para uma instituição de qualidade, podemos entender que:

a educação, como prática tem que criar condições para que todos desenvolvam suas capacidades e aprendam os conteúdos necessários para construir instrumentos de compreensão da realidade $e$ de participação em relação social, políticas $e$ culturais diversificadas, possibilitando 
condições para o exercício da cidadania na construção de uma sociedade democrática e não excludente (MEC/SEF, 1997, p.126).

Nesse contexto de desafios e busca pela qualidade na educação de seus discentes, a unidade escolar pauta seus trabalhos pedagógicos e suas pesquisas educacionais por uma proposta de educação baseada num trabalho de equipe e em consonância com os preceitos legais oriundos dos órgãos administrativos da qual é integrante. Nas suas avaliações, ela disponibiliza um leque de opções para privilegiar todos os alunos e traz também ao longo do ano recuperações organizadas de forma paralela, quando da não apropriação dos conteúdos. Esse modelo está além de uma visão reducionista trazida pelas provas padronizadas e medidores externos, caracterizando uma busca constante por aprendizagens significativas.

\section{Análises dos dados}

Os dados abaixo se referem à análise das respostas dadas pelos professores, no questionário utilizado como instrumento de coleta de dados. Traremos as perguntas realizadas, não sendo estas em uma sequência de aplicação, e um resumo das respostas dadas pelos participantes, fechando com uma análise das pesquisadoras ao tema recorrente.

Segundo a equipe pedagógica da unidade escolar pesquisada, a primeira reação em 2009 ao resultado apresentado pelo IDEB foi de muita tristeza: "Foi muito desagradável ver nossa escola na televisão com esta notícia".( Técnica Pedagógica, 2009). Essa frase deu início a uma busca por mudança, afinal o resultado teria que ser outro. A equipe pedagógica destacou como prioridade as questões pedagógicas, conforme constatamos na fala da Técnica da escola é preciso aproveitar melhor os 45 minutos de aula, referindose ao tempo em que as crianças passam na escola tendo aulas nas diversas disciplinas. $\mathrm{O}$ educador Paulo Freire (1996, p.43) concorda quando afirma que: "pensando criticamente a prática de hoje ou de ontem é que se pode melhorar a próxima prática".

A primeira pergunta objetivava saber se a unidade escolar promoveu alguma mudança na forma de conduzir o processo pedagógico a partir do resultado do IDEB de 2009. Quais mudanças? De acordo com a equipe pedagógica da escola, as mudanças ocorridas desde o ano de 2009 foram muitas. Primeiramente a equipe se reuniu e organizou um trabalho com o objetivo de trazer maiores informações sobre a Prova Brasil, pois, para os profissionais da unidade escolar, os alunos desconheciam a organização dos testes padronizados, bem como seus conteúdos, gerando um desconforto no momento da realização das provas, o que, segundo a opinião da maioria dos entrevistados, poderia ser um dos motivos do baixo rendimento e do resultado abaixo do esperado. O argumento foi de que quando são treinados previamente os resultados dos alunos são melhores. Corroborando com essa afirmação, Campos (2003, p.117) elucida que a preparação para um teste ou outro processo de verificação traz um desafio que melhora o desempenho dos alunos, qual seja:

Frequentemente os testes, ou outros processos de verificação da aprendizagem, são considerados como incentivos. Muitos professores acreditam que se o estudante sabe que vai ser testado, em qualquer assunto, estudará muito mais e, consequentemente, aprenderá mais (CAMPOS, 2003, p.117).

Diante dessa perspectiva, a equipe destaca como primordial para a melhoria da nota do IDEB em 2011 a criação de simulados, duas vezes ao ano, com questões semelhantes àquelas contidas na Prova Brasil. Dentro desse contexto destaca-se o treino realizado para preencher o gabarito, pois, na hora de passar as respostas para o cartão, os alunos não compreendiam a sequência da numeração e acreditavam estar nessa atitude a maioria das questões incorretas da prova, ocasionando o baixo índice no resultado final. Outro fator que muito contribuiu foram as frequentes advertências em outras avaliações, por parte dos professores, com a seguinte afirmação: "prestem atenção, pois pode cair na prova do IDEB”. Essas exortações deixavam os alunos mais conscientes e atentos ao que estava sendo trabalhado e avaliado. Devido a essa preparação, segundo o professor de Língua Portuguesa da instituição, os alunos estavam seguros, conscientes e extremamente preparados para a prova, o que consequentemente gerou melhores resultados.

Destacou-se também, como um fator decisivo para a melhoria da aprendizagem nesse contexto escolar, o incentivo à leitura e ao raciocínio lógico, com projetos específicos nessas áreas desenvolvidas pelos professores, no contra turno, dentro do programa Mais educação. Os referidos projetos tinham ampla aceitação entre os 
docentes, materiais pedagógicos disponibilizados pela equipe gestora e eram submetidos semanalmente à apreciação por parte dos professores em reuniões onde eram discutidos os acertos e percalços do projeto, numa clara evidência da importância do trabalho coletivo.

Além de fatores de cunho pedagógico, foi elencada como relevante a implantação no espaço físico da escola, de salas ambientes. Esses espaços são pensados para cada disciplina, onde o professor permanece durante todo o tempo diário de trabalho, sendo os alunos a fazerem as trocas a cada 45 minutos. Dessa forma, o ambiente é preparado para a aprendizagem dos conteúdos propostos para a disciplina, os livros didáticos e paradidáticos estão sempre expostos para consultas e o professor está disponível num ambiente propício para esclarecimento de dúvidas.

Não pode ser esquecido como um fator de extrema importância destacado pelos docentes o apoio pedagógico proporcionado aos professores e alunos pela equipe pedagógica da escola. Apoio no sentido de se fazer presente em sala de aula, buscar material didático para diversificar as práticas pedagógicas, reuniões com pais de alunos, conscientizando-os da importância de estarem em constante monitoramento das dificuldades e avanços escolares de seus filhos. Como retorno desse trabalho, a equipe pedagógica ao longo do ano letivo sempre expôs para a comunidade escolar os resultados obtidos através das mudanças ocorridas na escola. Como nos coloca Lima (2007) sobre a importância de coesão e de participação em discussões desta natureza:

Importante que as pessoas que ocupam cargos de liderança, como gestor, coordenador ou outro funcionário que vai coordenar os trabalhos precisa despir- se de posicionamento predominantemente autocrático para possibilitar o desenvolvimento de um clima em que todos contribuam com ideias, críticas, encaminhamentos (LIMA 2007 p.85).

$\mathrm{O}$ autor destaca o relevante papel dos coordenadores no trabalho pedagógico da escola: ele deve ter clareza e sentimento democrático em sua função junto aos professores, deve abrir mão de suas convicções pessoais e tornar a ideia coletiva, fazendo com que haja adesão de toda a equipe na direção de um trabalho comum para que os resultados sejam alcançados.
Indagamos se acreditavam que a rotatividade dos professores admitidos em caráter temporário (ACT), por não serem efetivos na unidade escolar e estar a cada ano em uma escola diferente, e serem aos cargos administrativos de indicação política influenciam no processo pedagógico de uma instituição de ensino. Podemos destacar que alguns profissionais acreditam que determinadas mudanças podem trazer ganhos, dando como exemplo a mudança de gestão, sendo esta, a atual, uma profissional, com o olhar direcionado às questões pedagógicas, auxiliando os professores no processo de ensino e de aprendizagem dos alunos. A rotatividade dos profissionais na escola foi evidenciada como de extrema relevância na questão de gestão. Por outro lado, existe a rotatividade como fator negativo, na questão professor, que pode ser evidenciado nas palavras de uma das entrevistadas: "A rotatividade de professores dificulta as estratégias de melhorias em longo prazo, sendo que não se estabelecem vínculos". "Quando existe muita transição de pessoas, o avanço é muito mais lento." "E muitas retomadas acabam interferindo no resultado final". Outro depoimento destaca que: "A rotatividade atinge profundamente a escola, pois a permanência do docente na instituição garante um maior comprometimento com aquilo que se ensina, com as ações pedagógicas tomadas e com as atitudes relacionadas ao processo de ensino $\mathrm{e}$ aprendizagem”.

Podemos enfatizar, portanto, que algumas mudanças de profissionais nas escolas agregam um diferencial no processo pedagógico e outras rompem com trabalhos em equipe previamente pensados e essas rupturas dificultam, mas não inviabilizam, como constatamos pela pesquisa, o andamento dos trabalhos.

A seguinte pergunta foi respectivamente sobre o assunto deste trabalho, assim elaborada: você acha importante a aplicação de avaliações externas, como a Prova Brasil, para a tomada de decisões quanto ao processo pedagógico das escolas? Os participantes da pesquisa de maneira geral acreditam ser essa uma forma importante para se pensar e repensar a tomada de decisões nas escolas, mas deixam claro que não deve ser somente através desses momentos pontuais de avaliação que a escola deve se reestruturar.

A escola é uma das instituições que tem como função essencial contribuir para a transformação da realidade social, 
proporcionando condições aos que nela atuam de desenvolver o senso crítico através da reflexão, para que possam agir de forma consciente exercendo sua plena cidadania (PPP, 2012, p. 18).

Sendo uma instituição formadora deve apressar as articulações para que as transformações aconteçam e os objetivos sejam alcançados mediante participação de todos. As tomadas de decisões em torno do aprendizado e emancipação dos alunos devem ultrapassar os limites das avaliações que servem como ranking nacional, como reforça a afirmação de uma das entrevistadas: "Criou-se um movimento em torno da melhoria do processo ensino/aprendizagem." A fala "criou-se" leva-nos a entender que as ações focadas na melhoria da aprendizagem, só foram possíveis mediante as exigências do sistema, nesse momento, as metas do IDEB.

Especificamente sobre o Índice do Desenvolvimento da Educação Básica-IDEB, foi elaborada a seguinte pergunta: Você professor, gestor ou técnico pedagógico, conhece o IDEB? Se a resposta for afirmativa, o que você sabe sobre o indicador? Pelas respostas obtidas nesta pergunta, ficou evidente o total conhecimento desse indicador de avaliação externa. Os professores não só o conhecem como formulam suas críticas, como pode ser comprovado na afirmação que segue: "É imposição de entidades internacionais. Tem relativa eficácia, não são pesados muitos fatores e escraviza a escola a manter aprovação, muitas vezes a qualquer preço. Como fator positivo, gera discussões e corrida pelos melhores lugares no ranking do ensino mais eficiente". Certamente a história da educação brasileira é marcada por acordos com organismos internacionais, ONU, UNESCO, OCDE, que na maioria das vezes atendem às exigências do mercado através do banco mundial (LAVAL 2003), tornando a escola cada vez mais competitiva e afastando-se de sua função primordial, que é ensinar. Conscientes dessas questões históricas, os professores da escola pesquisada assumem como fator positivo a prova do IDEB, pois este articula a busca por melhores resultados, voltando-se totalmente ao desempenho de todos os alunos, mas mantendo a consciência crítica acerca do que existe nas entrelinhas desses referenciais. Ao IDEB deve ser agregada uma série de outros resultados e expressões de qualidade que possam de fato desencadear e concretizar a educação com a qualidade que almejamos.

\section{Considerações Finais}

A realização desta pesquisa trouxe-nos importantes reflexões sobre as questões educacionais em nossa rede de ensino, se com as mudanças para aumentar o IDEB dessa escola foram atitudinais, boa parte dos problemas foram resolvidos. Sabemos, porém, que pesam sobre a qualidade do ensino as relações de trabalho existentes nas escolas, frutos de uma correlação entre $\mathrm{o}$ apoio às atividades pedagógicas entre docentes e discentes, bem como a infraestrutura oferecida aos alunos. Obviamente, manter uma estrutura escolar requer investimentos financeiros por parte do governo, políticas publicas que deem conta da estrutura humana, formação continuada e plano de salário e carreira. Tudo isso influencia no processo ensino aprendizagem. Segundo Nóvoa (2002, p. 23), “o aprender contínuo é essencial, se concentra em dois pilares: a própria pessoa, como agente, e a escola, como lugar de crescimento profissional permanente". Deve haver, portanto, a preocupação com a formação continuada dos profissionais que atuam nesse espaço, trazendo de forma reflexiva a melhor forma de gerenciar o conhecimento desenvolvimento na escola.

Como ponto de partida para as considerações finais, destacamos como ação relevante uma atitude diferente e coletiva tomada pela EEB Senador Rodrigo Lobo, que, num olhar minucioso, destacou como principal problema para o baixo rendimento na avaliação externa, a necessidade de um melhor aproveitamento do tempo escolar, melhorando e aperfeiçoando as práticas pedagógicas realizadas na escola, tornando-as práticas coletivas com envolvimento de toda equipe escolar. Com isso não se afirma que a escola não necessite dos investimentos enunciados, mas, neste caso, um olhar pedagogicamente correto contribuiu de forma relevante para a melhoria do processo de aprendizagem. Esse trabalho coletivo pode ser exemplificado pelos modelos de projetos realizados pela escola, nos quais houve o envolvimento não só das disciplinas de Língua Portuguesa e de Matemática, disciplinas contempladas nas avaliações da Prova Brasil, pois os profissionais sabiam que, se se limitassem apenas aos conhecimentos nessas duas áreas, não trariam um conjunto de conhecimentos aos quais as crianças têm direito de acesso, nem tampouco trariam uma melhoria significativa, pois o aprendizado se desenvolve num conjunto de saberes onde cada um faz a sua parte. 
O trabalho coletivo e a presença efetiva da coordenação pedagógica na busca pela articulação dos saberes entre os profissionais e o total apoio às propostas de mudanças almejadas pela equipe, como salas ambientes, material didático diferenciado, simulados e uma sintonia na fala dos professores quando o assunto era Prova Brasil, foram fatores essenciais não só para a mudança do índice como para uma nova postura diante do fazer pedagógico. Isso trouxe sem dúvida benefícios e bons resultados. Como destaca BAKHTIN (1999), a com os vínculos "materiais e objetivos" formamos uma "coletividade", ou seja, quando um grupo toma consciência de sua problemática e assume "a atividade mental de nós" será visivelmente expressada em atitudes coletivamente compartilhadas, e as ações individuais tornam-se coletivas quando o objetivo é unificado. Dessa perspectiva, a coletividade assume o papel principal e as mudanças aparecem.

Muito se tem discutido sobre a importância do coletivo no ambiente escolar, mas o fazer coletivo implica desejos, ou seja, desejos de mudanças por parte de todos os envolvidos no processo; foi esse desejo que permeou os trabalhos coletivos da escola Senador Rodrigo Lobo ao decidirem melhorar a nota do IDEB, articulados com as ações da coordenação pedagógica da escola.

Sobre a presença do coordenador pedagógico no processo de mudanças levantados na referente pesquisa, reportamo-nos ao que diz Saviani, 1985, “[...] cabe o domínio das formas através das quais o saber sistematizado é convertido em saber escolar". Ele fala aos profissionais responsáveis pelo pedagógico da escola e afirma ainda que esse saber escolar torna-se transmissível e assimilável na relação professor-aluno a partir do momento que ele é reestruturado na realidade escolar. Ao propor reflexões e organização do tempo em sala de aula, elaboração de projetos educacionais e estudo sobre a prova do IDEB e articulando os saberes dos profissionais da escola para promover o trabalho coletivo, entendemos que a coordenação pedagógica da escola Senador Rodrigo Lobo tem construído um saber escolar, como aponta Saviani.

Outra questão também digna de referência como promotora da melhoria foi sem dúvida a inserção no programa Mais Educação, um programa do governo federal que amplia o tempo escolar. Como esse programa prevê aulas no contra turno de forma a ampliar a oferta de atividades curriculares, muitos projetos importante estão sendo desenvolvidos neste período. Foi criado um novo espaço para a biblioteca, onde os alunos podem pesquisar e desenvolver o gosto pela leitura, já que os livros estão sempre à disposição. A disciplina de matemática recebeu uma série de jogos matemáticos, nas quais o aluno desenvolve principalmente o raciocínio lógico e o trabalho em equipe. Outras disciplinas também foram contempladas nessa força tarefa de melhoria da qualidade na educação da unidade escolar, como aulas de artes, meio ambiente e esporte.

Diagnosticar é sem dúvida alguma uma das funções primordiais das avaliações externas, devendo ser vista, portanto, como possibilidade de construção de um sistema educacional articulado, a existência de mecanismos confiáveis de mensuração e verificação do rendimento escolar. Esses mecanismos, além de servirem como subsídios para uma verificação da aprendizagem no âmbito da unidade escolar, tornam imprescindíveis que seus resultados cheguem também até a comunidade escolar. Transmitir aos pais e responsáveis uma fonte de dados provenientes de mecanismos externos, formando com eles uma parceria e proporcionando uma compreensão global do desenvolvimento dos alunos é ganhar um aliado importante na busca pela qualidade das nossas escolas, como afirma a técnica pedagógica da unidade pesquisada: "quando apresentamos resultados, a comunidade abraça as ideias". Nessa perspectiva, a equipe gestora faz relatos periódicos, para a comunidade, dos projetos realizados pela escola através de exposições e amostras, nas quais a comunidade tem a oportunidade de conhecer as atividades feitas pelos seus filhos e interagir com os professores e convidados que se fazem presentes nos dias de socialização dos trabalhos.

Muitos educadores e especialistas em educação apontam nos livros e principalmente na mídia soluções mirabolantes, como ações tecnológicas com o uso de computadores nas salas de aulas para todos os alunos, como fundamentais para a melhoria da qualidade nas escolas brasileira, já que a mesma é preocupante, haja vista que o Brasil está na $88^{a}$ posição no ranking mundial da educação. Percebemos, porém, que iniciativas simples como as contempladas pela escola pesquisada podem reverter num ganho relevante tanto para os alunos que melhoram suas médias pontuais, numa prova específica, como também para os profissionais, que entenderam que ser professor e ocupar um espaço na sala de aula requer um trabalho contínuo buscando metodologias e 
estratégias de forma a possibilitar o aprendizado do aluno, assim como compreenderam que a profissão de Ser Professor exige um olhar para as questões sociais e políticas numa constante atualização e ressignificação do processo de ensino e um comprometimento ímpar no direcionamento das suas práticas pedagógicas. A pesquisa permite-no concluir que a escola encontrou um caminho importante de reflexão da prática pedagógica, de trabalho coletivo e de participação da comunidade para seguir adiante num processo contínuo de busca pela educação que a comunidade prioriza e acredita ser de qualidade para todos inseridos no processo escolar.

\section{Referências}

BAKHTIN, Mikhail. Marxismo e Filosofia da Linguagem. São Paulo: Hucitec, 1999.

BRASIL, Constituição Federativa do Brasil, 1988.

BRASIL, Lei de Diretrizes e Bases da Educação, 1996.

CAMPOS, Dinah Martins de Souza. Psicologia da Aprendizagem, Petrópolis, Vozes, 1987.

FREIRE, Paulo. Pedagogia da autonomia: saberes necessários à prática educativa. 20 ed. São Paulo: Paz e Terra, 1996.

LAVAL, Christian. A Escola Não é Empresa: o neoliberalismo em ataque ao ensino público. Ed. Planta, 2003.

LIMA, Paulo Gomes. SANTOS, Sandra Mendes dos. O coordenador Pedagógico na Educação Básica: Desafios e Perspectivas, Educare ET Educare, Revista da Educação. Vol.2 n 4, julho, 2007.

MEC, Ministério da Educação. INEP - Instituto Nacional de Estudos e Pesquisas. Disponível em: www.mec.gov.br, acesso em setembro de 2012.

NÓVOA, Antonio. (coord). Refletindo sobre educação continuada. Revista Nova Escola. Agosto de 2002.

SANTA CATARINA. Lei Complementar 170/98.

Resolução 112/2000.

Conselho Estadual de Educação.

SAVIANI, Dermeval. Sentido da Pedagogia e papel do Pedagogo. Revista ANDE, São Paulo, n. 9. P. 27-28, 1985.

PDE - Plano de

Desenvolvimento da Educação: Análise crítica da política do MEC. Campinas, SP: Autores Associados, 2009 (coleção Polêmicas do nosso tempo, 99).

SOCIOLOGIA: ensino médio/ Coordenação Amaury César Morães. Brasília: Ministério da Educação, Secretaria de Educação Básica, 2010 (Coleção Explorando o Ensino; v.15).

Sobre as autoras:

Inês Odorizzi Ramos: Mestre em Educação pela Universidade do Vale do Itajaí - UNIVALI. Graduada em História - UNIVALI. Professora bolsista na Universidade da região de Joinville - UNIVILLE. Funcionária Pública da rede estadual. Atua como Consultora Educacional na Gerência de Educação em Joinville SC.

Dulcelina da Luz Pinheiro Frasseto: Cursando Mestrado em Educação pela Universidade da Região de Joinville - UNIVILLE. Graduada em Pedagogia - ACE. Especialização em Educação Infantil e Séries Inicias. Funcionária pública, rede estadual. Atua como Consultora Educacional na Gerência de Educação em Joinville SC.

Recebido em: 10/2012

Aprovado em: 05/2013 